\title{
Adsorption of Phthalates on Municipal Activated Sludge
}

\author{
Hongbo Wang, ${ }^{1,2}$ Haining Li, ${ }^{1}$ Qicheng Song, ${ }^{1}$ Lili Gao, ${ }^{3}$ and Ning Wang ${ }^{1}$ \\ ${ }^{1}$ School of Municipal and Environmental Engineering, Shandong Jianzhu University, Jinan 250101, China \\ ${ }^{2}$ Shandong Co-Innovation Center of Green Building, Jinan, China \\ ${ }^{3}$ Shandong Urban and Rural Planning Design Institute, Jinan, Shandong 250013, China
}

Correspondence should be addressed to Ning Wang; wangning@sdjzu.edu.cn

Received 25 September 2016; Revised 30 November 2016; Accepted 19 December 2016; Published 9 January 2017

Academic Editor: Athanasios Katsoyiannis

Copyright (C) 2017 Hongbo Wang et al. This is an open access article distributed under the Creative Commons Attribution License, which permits unrestricted use, distribution, and reproduction in any medium, provided the original work is properly cited.

\begin{abstract}
Phthalates (PAEs) are commonly detected in discharge of municipal wastewater treatment plants. This study investigated the removal of six typical PAEs with activated sludge and the results revealed that concentrations of aqueous PAEs decreased rapidly during the beginning $15 \mathrm{~min}$ and reached equilibrium within 2 hours due to the adsorption of activated sludge. The process followed first-order kinetic equation, except for dioctyl phthalate (DOP). The factors influencing the adsorption were also evaluated and it was found that higher initial concentrations of PAEs enhanced the removal but affected little the adsorption equilibrium time. The adsorption of PAEs favored lower operating temperature (the optimum temperature was approximately $25^{\circ} \mathrm{C}$ in this research), which could be an exothermic process. Additionally, lower aqueous $\mathrm{pH}$ could also benefit the adsorption.
\end{abstract}

\section{Introduction}

Phthalates (PAEs), a group of artificial chemicals, are characterized with low water solubility, low volatility, and low temperature resistance, which are widely used in agriculture, cosmetics, coatings, and so forth [1]. Multiple studies have reported that PAEs enter human body through breathing, eating, and skin contacting and possibly cause mutagens, teratogens, and carcinogens [2]. Major developed countries recognized PAEs as a group of serious pollutants. The compounds were found in atmosphere [3], water [4], soil [5], and biological agents, including human body [6]. Owing to the long half-life time in environment and strong bioaccumulation tendency, PAEs are thought to be a group of persistent organic pollutants (POPs). The US EPA listed six PAEs as priority toxic pollutants, including dimethyl phthalate (DMP), diethyl phthalate (DEP), dibutyl phthalate (DBP), benzyl butyl phthalate (BBP), di-2-ethylhexyl phthalate (DEHP), and dioctyl phthalate (DOP), and China also regulated three PAEs (DEP, DMP, and DOP) as environmental priority control pollutants. Previous researchers have reported that municipal sewage treatment plants are major pathway of PAEs into the environment [7-9].
To control the pollutants, adsorption is a popular and effective method to separate PAEs from aqueous phase and many sorbents have been considered, such as activated carbon, polymeric adsorbent, carbon nanotube, chitosan, and seaweed. The adsorption of DBP on activated carbon is spontaneous and endothermic and favors higher temperatures [10]. Polymer resins were described to eliminate aqueous DEP and the adsorption processes are limited by both film and intraparticle diffusions [11]. Nanomaterials, such as carbon nanotube, were also found to adsorb DMP and DEP, and the performance is influenced by nanotube size, surface modification, and adsorption temperature [12]. Chen et al. [13] conducted a pilot column test of six PAEs removal by chitosan and the breakthrough times vary from 4.5 to $8 \mathrm{hrs}$. Seaweed, a biomass adsorbent, could remove DEHP with the adsorption capacity of $5.68-6.54 \mathrm{mg} / \mathrm{g}$ in a batch test [14]. Although the mentioned adsorbents could effectively eliminate aqueous PAEs, the economic cost must be considered in practical application and cheaper alternative is preferred.

One substitution would be activated sludge, yellowishbrown flocculants and particulates, which was confirmed to adsorb and accumulate PAEs from municipal wastewater $[9,15,16]$, due to the composition of microbial 
communities characterized with porous structure and extracellular polymers resulting in large surface area, strong adsorption, and plentiful biological activities. Previous research [17] showed DEP $(0.73 \mathrm{mg} / \mathrm{g})$ and DBP $(17.6 \mathrm{mg} / \mathrm{g})$ are substantially adsorbed by activated sludge and higher hydrophobicity of PAEs promotes the process. Additionally, the high octanol/water partition coefficient of PAEs assists the accumulation in biomass [18], resulting in greater tendency to attach on activated sludge. Besides, as a solid waste, sludge was an economic method to control the aqueous PAEs.

This research symmetrically investigated the adsorption of six PAEs on activated sludge and the influencing factors to improve the removal rate. The partitions between sludge and water were also studied.

\section{Method and Materials}

2.1. Chemicals and Sample Preparation. The regents used in this research were listed as follows: $2000 \mu \mathrm{g} / \mathrm{L}$ of six PAE standard solutions, including DMP, DEP, DBP, DEHP, DOP, and BBP (Sigma-Aldrich, USA); methanol (HPLC grade, America world); dichloromethane (HPLC grade, Tianjin Kermel Chemical Reagent Co., Ltd., China); acetone and hydrochloric acid (GR, Tianjin Kermel Chemical Reagent Co., Ltd., China); and ultra-pure water (resistivity $=18.6 \mathrm{M}$ omega, $\mathrm{pH}=2.5$ ).

Experimental water and activated sludge: The experimental water was made with glucose as carbon source, $\mathrm{NH}_{4} \mathrm{Cl}$ as nitrogen source, certain amount of $\mathrm{Mg}, \mathrm{P}, \mathrm{Fe}, \mathrm{Ca}$, and $\mathrm{Zn}$ ions as trace nutrients, and sodium azide as inhibitor, following the instructions of pervious research [19]. The water was adjusted to COD of $300 \mathrm{mg} / \mathrm{L}$ and total nitrogen of $50 \mathrm{mg} / \mathrm{L}$ to mimic municipal wastewater. The activated sludge sample was taken from a secondary sediment tank of Jinan water treatment factory. Before experiments, the sewage was triply rinsed and washed with distilled water to avoid the disturbance of background PAEs.

\subsection{Methodology}

Adsorption Experiment. All experiments were carried out in flasks stirred with a thermostatic oscillator (SHA-CA, Jinan Jingke Corporation, China) at $130 \mathrm{rpm}$. The sludge concentration (MLSS) was adjusted to $4000 \mathrm{mg} / \mathrm{L}$ (typical concentration in activated sludge tank of a municipal wastewater treatment plant) with prepared experimental water and a certain amount of mixed PAE standard solution. Subsequently, at expected time spans, certain amounts of mixture of sludge and water were separated by centrifuging at high speed rpm and filtrating with $0.45 \mu \mathrm{m}$ glass fiber. The filtrate (water) was adjusted to $\mathrm{pH}$ equal to 2.5 with hydrochloric acid and stored in sealed glass bottles at $4^{\circ} \mathrm{C}$ and the remaining activated sludge was frozen and dried for extraction.

Extraction of PAEs from Water. Solid phase extraction was applied with C18 column (Supelco, USA), which was sequentially cleaned and activated by dichloromethane, methanol, and ultra-pure water before usage. The water sample passed the C18 column, which was dried by vacuum to remove residual moisture after the extraction. The target PAEs were eluted into a small test tube with dichloromethane, dehydrated with anhydrous sodium sulfate, and concentrated to $1 \mathrm{ml}$ with nitrogen gas blower (KL-512J, Beijing Kang Lin Science \& Technology Corporation, China) for further analysis.

Extraction of PAEs from Sludge. Soxhlet extraction method, modified from EPA method 8061A, was employed for the dry sludge sample. After being added with anhydrous sodium sulfate and ground until passing through a $1 \mathrm{~mm}$ sieve, the sample was packed with filter paper and placed in Soxhlet extraction tube, which was rinsed and extracted with acetone and dichloromethane (volume ratio $1: 1$ ) mixture at $60^{\circ} \mathrm{C}$ for 24 hours. The extracts were concentrated to $5 \mathrm{ml}$ with rotary evaporator before being purified with anhydrous $\mathrm{Na}_{2} \mathrm{SO}_{4}$ silica gel- $\mathrm{Al}_{2} \mathrm{O}_{3}$ chromatography column, which was eluted with dichloromethane for three times. Then, the volume of eluent was reduced to $1 \mathrm{ml}$ by rotary evaporating and nitrogen blowing.

Instrument Analysis. PAEs were quantitatively determined with GC/MS (QP2010 Plus, Shimadzu Corporation, Japan). The column temperature was programed as follows: the initial temperature was $120^{\circ} \mathrm{C}$, immediately raised to $300^{\circ} \mathrm{C}$ at $10^{\circ} \mathrm{C} / \mathrm{min}$, and held for $2 \mathrm{~min}$. Inlet temperature was $300^{\circ} \mathrm{C}$. The sample inject volume was $1 \mu \mathrm{L}$ and the split ratio was $20: 1$. The carrier gas was helium with the flow rate of $1 \mathrm{~mL} / \mathrm{min}$. The pressure of the inlet column was $106 \mathrm{KPa}$. The bombardment source was $\mathrm{El}+$ with the ion source temperature of $250^{\circ} \mathrm{C}$. SIM mode was used and the details of mass spectrum characteristic fragment ions and retention time of the peaks were shown in Table 1 .

For the purpose of QA/QC, all the experimental processes were triplicated to minimize operational error. The detection limits were concentrations when signal/noise was three. The spiked recovery of PAEs was $83.20 \%-111.78 \%$ with standard deviation of $2.29 \%-8.99 \%$.

\section{Results and Discussion}

3.1. Effect of Initial Concentration of PAEs. Different initial concentrations of adsorption experiments were chosen as $40 \mu \mathrm{g} / \mathrm{L}$ and $80 \mu \mathrm{g} / \mathrm{L}$, and the results are shown in Figure 1. Both concentration profiles were similar: at the beginning 15 mins, all PAEs decreased sharply; during $15 \mathrm{~min}-2 \mathrm{~h}$, most PAEs kept going down slowly; after $2 \mathrm{hr}$, PAEs fluctuated in a small concentration range. Then, it is likely considered that the adsorption equilibrium was reached in approximately $2 \mathrm{~h}$. For the initial concentration of $40 \mu \mathrm{g} / \mathrm{L}$, DMP showed an ascending trend after $15 \mathrm{~min}$, while other PAEs were either relatively stable or slightly decreased as time elapsed; for initial concentration of $80 \mu \mathrm{g} / \mathrm{L}, \mathrm{DMP}, \mathrm{DBP}$, and DOP showed slightly increasing trend, while DEP and DEHP were stable and BBP cannot be detected after 15 mins. Slow desorption of PAEs from sludge might contribute to the observation in a longer time experiment [20]. 
TABLE 1: Quantitation information of PAEs for GC-MS.

\begin{tabular}{lcccc}
\hline PAEs & Retention time $(\mathrm{min})$ & Qualitative ion $(\mathrm{m} / z)$ & Quantitative ion $(\mathrm{m} / z)$ & Auxiliary quantitative ion $(m / z)$ \\
\hline DMP & 5.27 & $163: 164: 92: 194$ & 163 & 164,92 \\
DEP & 6.72 & $149: 177: 150: 105$ & 149 & 177 \\
DBP & 10.53 & $149: 150: 223: 205$ & 149 & 150 \\
BBP & 14.09 & $149: 206: 91: 123$ & 149 & 91 \\
DEHP & 15.58 & $149: 167: 279: 113$ & 149 & 167 \\
DOP & 17.07 & $149: 279: 150: 390$ & 149 & 150 \\
\hline
\end{tabular}

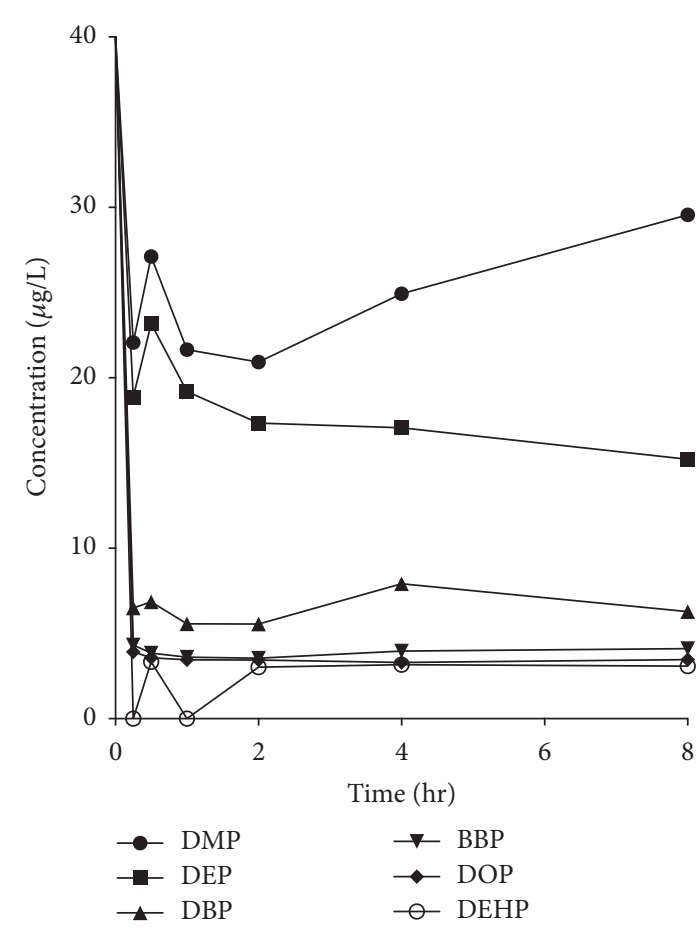

(a)

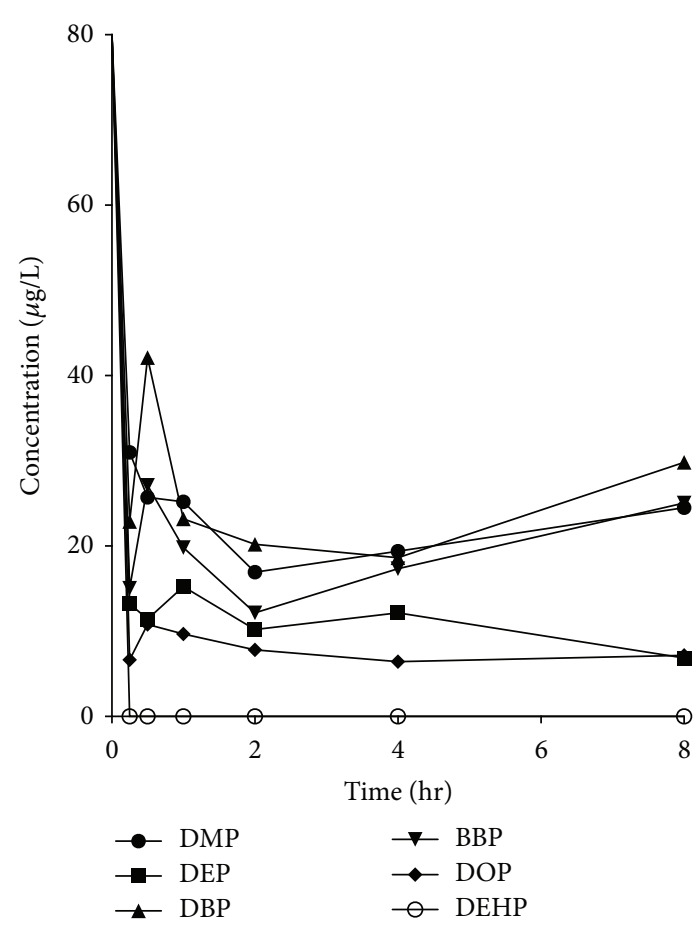

(b)

FIgURE 1: The change of PAEs in water phase over time with initial concentration of $40 \mu \mathrm{g} / \mathrm{L}$ (a) or $80 \mu \mathrm{g} / \mathrm{L}$ (b).

Figure 2 presents the adsorption capacities of activated sludge in two hours. Figure 2(a) shows that the adsorption capacity of activated sludge of 6 PAEs reached maximum in $0.5 \mathrm{hr}$ when initial concentration was $40 \mu \mathrm{g} / \mathrm{kg}$; adsorption capacity did not vary a lot during $0.5 \mathrm{hr}$ to $1 \mathrm{hr}$ but DEHP was not detected; during $1 \mathrm{hr}$ to $4 \mathrm{hr}$, PAEs in mud phase presented a downward trend, while, during $4 \mathrm{hr}$ to $8 \mathrm{hr}$, DEP, DBP, and DOP increased slightly and BBP were not detected. Figure 2(b) shows that the adsorption maximum occurred in $0.25 \mathrm{hr}$ when the initial concentration was $80 \mu \mathrm{g} / \mathrm{kg}$ and then showed a downward trend except that DEP kept stable. The decrease was mainly due to the sludge biological degradation [21]. The higher the initial concentration of PAEs, the stronger the adsorption of activated sludge, because of the diffusion force of greater concentration gradient in water. When reaching the equilibrium, the removal rate of DEHP was the highest, while the removal rate of DMP was lowest. Sludge adsorbed much less DMP and DEP than DOP and BBP.
In this research, the process of activated sludge adsorbing PAEs was fitted to first-order kinetics equation as follows:

$$
\begin{aligned}
C & =C_{0} \cdot e^{-k t}, \\
t_{1 / 2} & =\frac{\ln 2}{k},
\end{aligned}
$$

where $C(\mu \mathrm{g} / \mathrm{L})$ is the residual concentration of PAEs at time $t$, $C_{0}(\mu \mathrm{g} / \mathrm{L})$ is the initial concentration of PAEs, $k$ is degradation rate constant, and $t_{1 / 2}(\mathrm{~h})$ is the half-life of the degradation.

Equation (1) was transferred into (3) to obtain rate constants and half-life, shown in Table 2, by linearly fitting above data.

$$
\ln C=\ln C_{0}-k t
$$

Except for DOP, the removal process of other five PAEs basically was in accord with the first-order kinetics equation, 


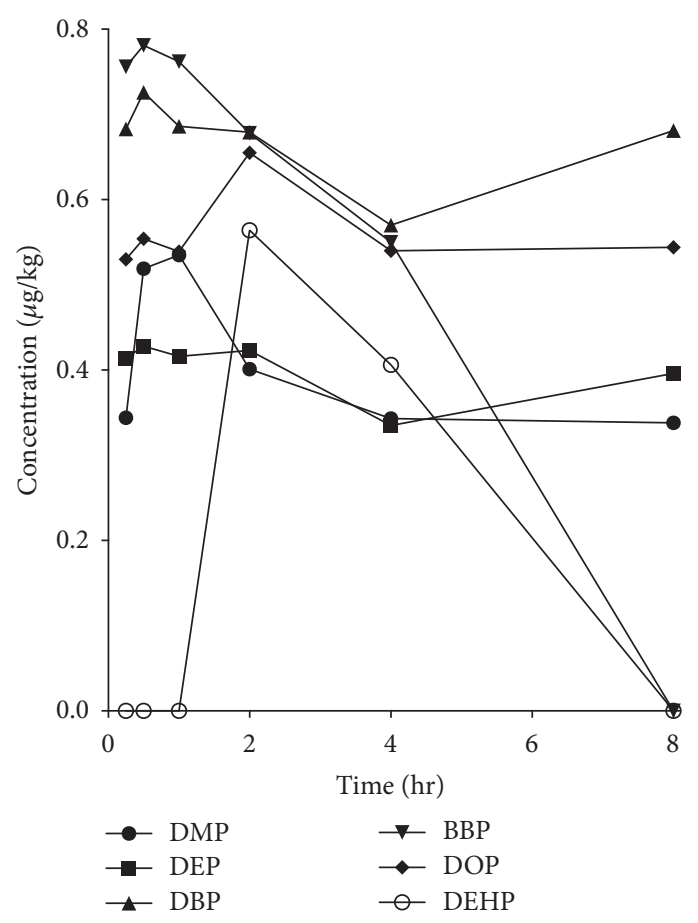

(a)

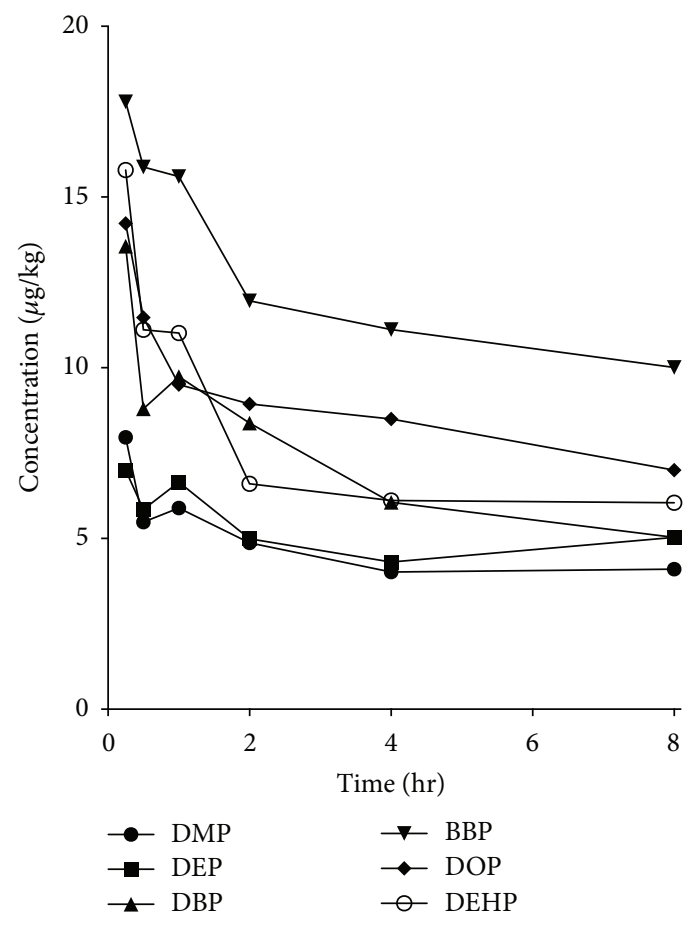

(b)

FIgURE 2: The change of PAEs in sludge phase over time with initial concentration of $40 \mu \mathrm{g} / \mathrm{kg}$ (a) or $80 \mu \mathrm{g} / \mathrm{kg}$ (b).

TABLE 2: The rate constants and half-life of activated sludge adsorbing PAEs fitting first-order reaction (initial PAE concentration was $80 \mu \mathrm{g} / \mathrm{L}$ ).

\begin{tabular}{|c|c|c|c|c|}
\hline Phthalate ester & Kinetic equations & $K\left(\mathrm{~h}^{-1}\right)$ & $t_{1 / 2}(\mathrm{~h})$ & $R^{2}$ \\
\hline DMP & $\ln C=-2.486 t+4.846$ & 2.486 & 0.279 & 0.9657 \\
\hline DEP & $\ln C=-1.872 t+4.106$ & 1.872 & 0.370 & 0.9380 \\
\hline DBP & $\ln C=-1.599 t+4.499$ & 1.599 & 0.433 & 0.9958 \\
\hline DEHP & $\ln C=-0.697 t+3.011$ & 0.697 & 0.994 & 0.9754 \\
\hline DOP & $\ln C=-1.023 t+3.815$ & 1.023 & 0.677 & 0.5657 \\
\hline BBP & $\ln C=4.629 t+4.361$ & 4.629 & 0.150 & 0.9630 \\
\hline
\end{tabular}

while the half-life and degradation rate constant were significantly different. The degradation rate constants were sorted in order: $k_{\mathrm{BBP}}>k_{\mathrm{DMP}}>k_{\mathrm{DEP}}>k_{\mathrm{DBP}}>k_{\mathrm{DOP}}>k_{\mathrm{DEHP}}$, while the order of molecular weight was DMP $<$ DEP $<$ $\mathrm{DBP}<\mathrm{BBP}<\mathrm{DOP}=\mathrm{DEHP}$. It implied that the molecular weight and structure of PAEs influenced the adsorption and degradation property of activated sludge. With the increase of molecular weight, carbon chain, and volume of PAEs, steric effect of biological reaction was increased. At the same time, the increase of molecular weight reduced the water solubility of PAEs, had an effect on utilizing microorganism in water, and caused the decline of biological degradation rate. Then the PAEs compete with each other for the adsorption sites on sludge, resulting in the different rate constants.

The mass balance analysis after $8 \mathrm{hr}$ adsorption is shown in Table 3. Except that DEHP, the most commercially applied phthalate [22], was majorly trapped on sludge, other PAEs lost more than one-third, which might result from the biological degrading though $\mathrm{NaN}_{3}$ was used to limit the activities of micrograms. It has been reported that about $36-42 \%$ removal of some PAE attributed to biodegradation of sludge in a nitrogen-removing sequencing batch reactor [21].

3.2. Effect of Temperature. The temperature effect is shown in Figure 3. Less aqueous PAEs remained when water temperature was $25^{\circ} \mathrm{C}$, while the concentration of PAEs in sludge decreased with temperature increasing. In water, the temperature affected more DEP and DMP, which were $34.35 \mu \mathrm{g} / \mathrm{L}$ and $30.39 \mu \mathrm{g} / \mathrm{L}$ at $25^{\circ} \mathrm{C}$, respectively, both significantly lower than those at $15^{\circ} \mathrm{C}$ and $35^{\circ} \mathrm{C}$. This may be due to the fact that, at the low temperature, the viscosity of PAEs solution and the diffusion rate of molecules were low, resulting in less PAEs adsorbed on the surface of activated sludge; when the temperature raised, the adhesion of the solution decreases became lower and the diffusion was accelerated; 
TABLE 3: Mass balance analysis in one-liter mixture solution.

\begin{tabular}{lcccc}
\hline Phthalate ester & Initial mass $(\mu \mathrm{g})$ & Remains in sludge $(\mu \mathrm{g})$ & Remains in water $(\mu \mathrm{g})$ & Loss $(\mu \mathrm{g})$ \\
\hline DMP & 80 & 16.4 & 24.49 & 39.11 \\
DEP & 80 & 20.12 & 6.85 & 53.03 \\
DBP & 80 & 20.12 & 29.82 & 30.06 \\
DEHP & 80 & 40.04 & 25.04 & 14.92 \\
DOP & 80 & 28 & 7.16 & 44.84 \\
BBP & 80 & 24.2 & 0 & 55.8 \\
\hline
\end{tabular}

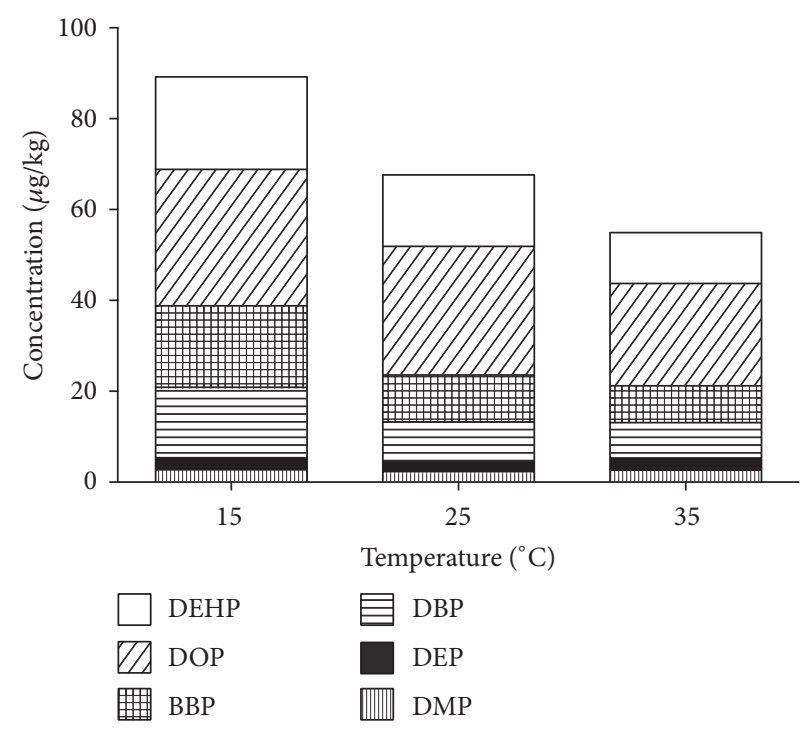

(a)

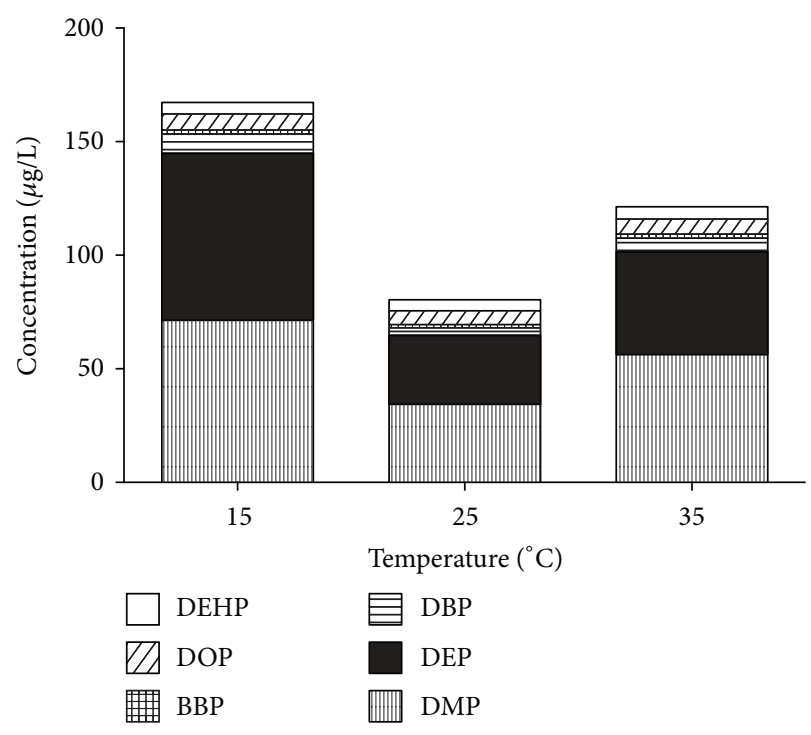

(b)

Figure 3: The concentrations of PAEs in sludge (a) and water (b) at different temperatures (initial concentration $=80 \mu \mathrm{g} / \mathrm{L}, \mathrm{pH}=7.0$, and experiment duration $=2 \mathrm{hrs}$ ).

but, when temperature went higher, desorption was strengthened since the activated sludge adsorption of PAEs is an exothermic process. For sludge, higher temperature would increase the bacterial activities, enhancing the degradation of PAEs.

3.3. Effect of $p H$. Different $\mathrm{pH}$ values might inhibit the activity of activated sludge adsorption of PAEs. The results are shown in Figure 4.

As shown in Figure 4(a), except BBP, PAEs in water showed a sharp decreasing as $\mathrm{pH}$ increased in the range of 5-9 but no significant change at $\mathrm{pH}$ of 9-11. The aqueous $\mathrm{pH}$ implies the concentrations of the $\mathrm{H}^{+}$and $\mathrm{OH}^{-}$, and the microbial floc surface of activated sludge is full of protein molecules, containing carbonyl groups $(-\mathrm{COOH})$. When the $\mathrm{OH}-$ content was high, $-\mathrm{COOH}$ would turn into $-\mathrm{COO}^{-}$, resulting in high negative potential on surface. The hydrolysis of PAEs created electropositive potential, meaning they were easy to be adsorbed on the activated sludge at higher $\mathrm{pH}$. As Figure 4(b) shows, the PAEs in mud concentration did not vary much along the $\mathrm{pH}$ range and showed no regular trend for all species.

\section{Conclusions}

The adsorption capacity of activated sludge was higher with the initial PAEs concentration of $80 \mu \mathrm{g} / \mathrm{L}$ than that of $40 \mu \mathrm{g} / \mathrm{L}$. Both adsorption isotherm profiles were similar: fast adsorption rate in the first $30 \mathrm{~min}$ and adsorption equilibrium during $2 \mathrm{hrs}$. The adsorption followed first-order kinetic rate.

The adsorption of PAEs on activated sludge favored $25^{\circ} \mathrm{C}$ in this study, and only DEP and DMP out of six PAEs were influenced significantly by temperature.

The aqueous PAEs concentrations decreased significantly in the $\mathrm{pH}$ range of 5-9 and kept relatively constant when the $\mathrm{pH}$ was in the range of 9-11.

\section{Competing Interests}

The authors declare that they have no competing interests. 


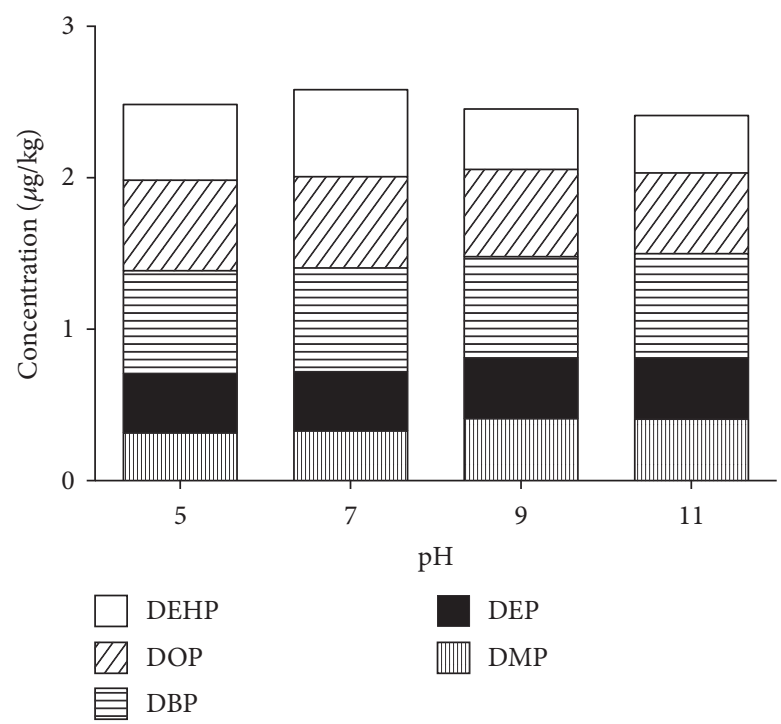

(a)

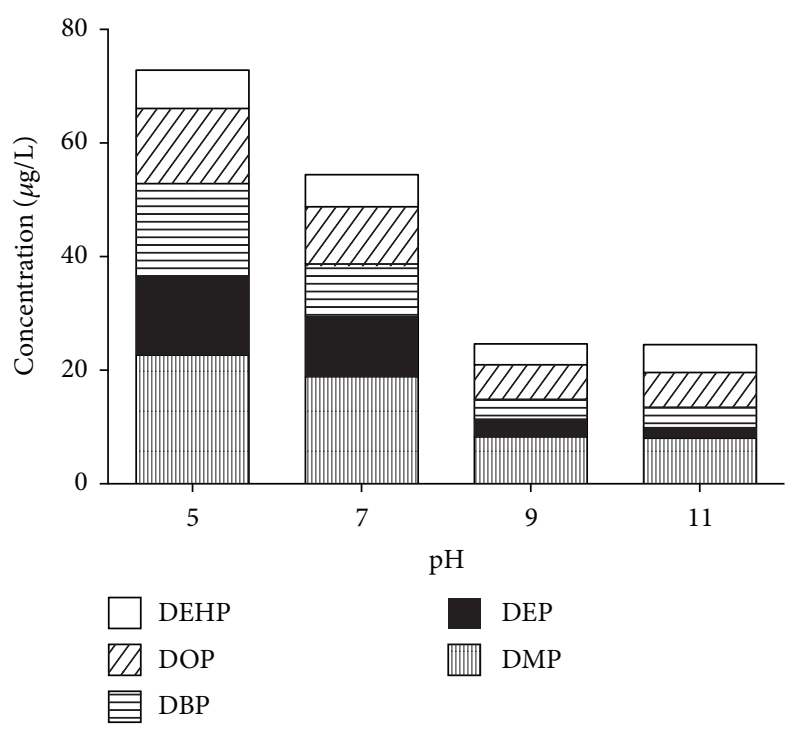

(b)

Figure 4: The concentrations of PAEs in sludge (a) and water (b) at different $\mathrm{pH}$ (initial concentration $=80 \mu \mathrm{g} / \mathrm{L}$, temperatures $=25^{\circ} \mathrm{C}$, and experiment duration $=2 \mathrm{hrs}$ ).

\section{Acknowledgments}

Funds for this work were provided by the National Natural Science Foundation of China (no. 21407097) and the Shandong Natural and Science Foundation (ZR2014EEM009).

\section{References}

[1] F. Alatriste-Mondragon, R. Iranpour, and B. K. Ahring, "Toxicity of di-(2-ethylhexyl) phthalate on the anaerobic digestion of wastewater sludge," Water Research, vol. 37, no. 6, pp. 1260-1269, 2003.

[2] M. Matsumoto, M. Hirata-Koizumi, and M. Ema, "Potential adverse effects of phthalic acid esters on human health: a review of recent studies on reproduction," Regulatory Toxicology and Pharmacology, vol. 50, no. 1, pp. 37-49, 2008.

[3] M. Wensing, E. Uhde, and T. Salthammer, "Plastics additives in the indoor environment-flame retardants and plasticizers," Science of the Total Environment, vol. 339, no. 1-3, pp. 19-40, 2005.

[4] D. Gao, Z. Li, Z. Wen, and N. Ren, "Occurrence and fate of phthalate esters in full-scale domestic wastewater treatment plants and their impact on receiving waters along the Songhua River in China," Chemosphere, vol. 95, pp. 24-32, 2014.

[5] L. He, G. Gielen, N. S. Bolan et al., "Contamination and remediation of phthalic acid esters in agricultural soils in China: a review," Agronomy for Sustainable Development, vol. 35, no. 2, pp. 519-534, 2015.

[6] E. Bruns-Weller and J. Pfordt, "Determination of phthalic acid esters in foodstuffs, mother's milk, dust, and textiles," Umweltwissenschaften und Schadstoff-Forschung, vol. 12, no. 3, pp. 125130, 2000.

[7] S. Amir, M. Hafidi, G. Merlina et al., "Fate of phthalic acid esters during composting of both lagooning and activated sludges," Process Biochemistry, vol. 40, no. 6, pp. 2183-2190, 2005.
[8] H.-F. Cheng, M. Kumar, and J.-G. Lin, "Degradation kinetics of di-(2-ethylhexyl) phthalate (DEHP) and organic matter of sewage sludge during composting," Journal of Hazardous Materials, vol. 154, no. 1-3, pp. 55-62, 2008.

[9] M. Barret, L. Delgadillo-Mirquez, E. Trably et al., "Anaerobic removal of trace organic contaminants in sewage sludge: 15 years of experience," Pedosphere, vol. 22, no. 4, pp. 508-517, 2012.

[10] Z. Q. Fang and H. J. Huang, "Adsorption of di-n-butyl phthalate onto nutshell-based activated carbon. Equilibrium, kinetics and thermodynamics," Adsorption Science \& Technology, vol. 27, no. 7, pp. 685-700, 2009.

[11] Z. Xu, W. Zhang, B. Pan, L. Lv, and Z. Jiang, "Treatment of aqueous diethyl phthalate by adsorption using a functional polymer resin," Environmental Technology, vol. 32, no. 2, pp. 145-153, 2011.

[12] W. Den, H. C. Liu, S. F. Chan, K. T. Kin, and C. Huang, "Adsorption of phthalate esters with multiwalled carbon nanotubes and its applications," Journal of Environmental Engineering and Management, vol. 16, no. 4, pp. 275-282, 2006.

[13] C.-Y. Chen, C.-C. Chen, and Y.-C. Chung, "Removal of phthalate esters by $\alpha$-cyclodextrin-linked chitosan bead," Bioresource Technology, vol. 98, no. 13, pp. 2578-2583, 2007.

[14] H. W. Chan, T. C. Lau, P. O. Ang, M. Wu, and P. K. Wong, "Biosorption of di(2-ethylhexyl)phthalate by seaweed biomass," Journal of Applied Phycology, vol. 16, no. 4, pp. 263-274, 2004.

[15] Q.-Y. Cai, C.-H. Mo, Q.-T. Wu, Q.-Y. Zeng, and A. Katsoyiannis, "Occurrence of organic contaminants in sewage sludges from eleven wastewater treatment plants, China," Chemosphere, vol. 68, no. 9, pp. 1751-1762, 2007.

[16] X.-Z. Meng, Y. Wang, N. Xiang et al., "Flow of sewage sludgeborne phthalate esters (PAEs) from human release to human intake: implication for risk assessment of sludge applied to soil," Science of the Total Environment, vol. 476-477, pp. 242-249, 2014.

[17] H. H. P. Fang and H. Zheng, "Adsorption of phthalates by activated sludge and its biopolymers," Environmental Technology, vol. 25, no. 7, pp. 757-761, 2004. 
[18] P. Serôdio and J. M. F. Nogueira, "Considerations on ultra-trace analysis of phthalates in drinking water," Water Research, vol. 40, no. 13, pp. 2572-2582, 2006.

[19] J. Zhao, Y. Li, C. Zhang, Q. Zeng, and Q. Zhou, "Sorption and degradation of bisphenol A by aerobic activated sludge," Journal of Hazardous Materials, vol. 155, no. 1-2, pp. 305-311, 2008.

[20] X. Vecino, L. Rodríguez-López, J. M. Cruz, and A. B. Moldes, "Sewage sludge polycyclic aromatic hydrocarbon (PAH) decontamination technique based on the utilization of a lipopeptide biosurfactant extracted from corn steep liquor," Journal of Agricultural and Food Chemistry, vol. 63, no. 32, pp. 7143-7150, 2015.

[21] S. K. Marttinen, M. Ruissalo, and J. A. Rintala, "Removal of bis (2-ethylhexyl) phthalate from reject water in a nitrogenremoving sequencing batch reactor," Journal of Environmental Management, vol. 73, no. 2, pp. 103-109, 2004.

[22] M. Julinová and R. Slavík, "Removal of phthalates from aqueous solution by different adsorbents: a short review," Journal of Environmental Management, vol. 94, no. 1, pp. 13-24, 2012. 

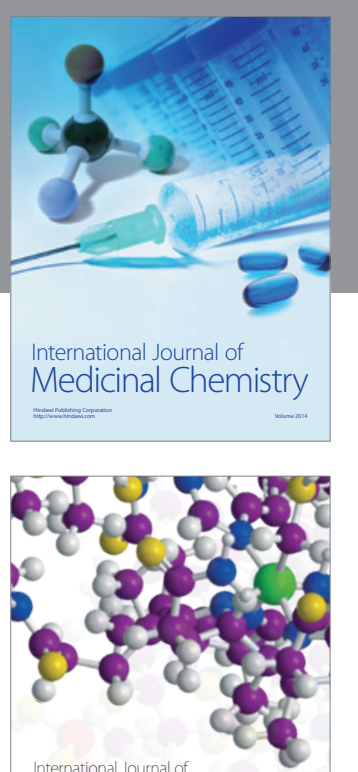

Carbohydrate Chemistry

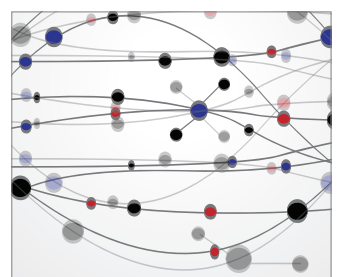

The Scientific World Journal
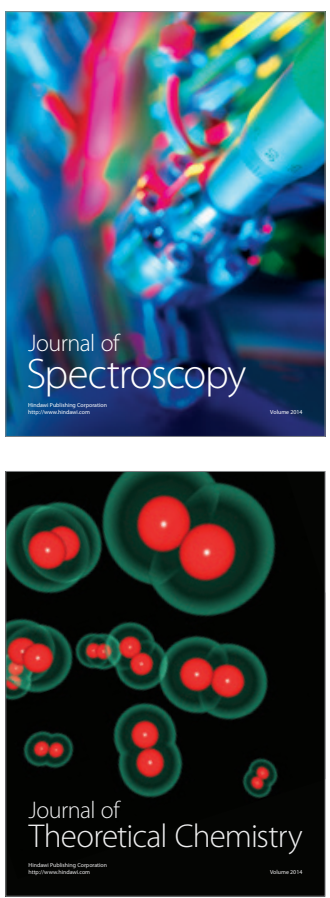
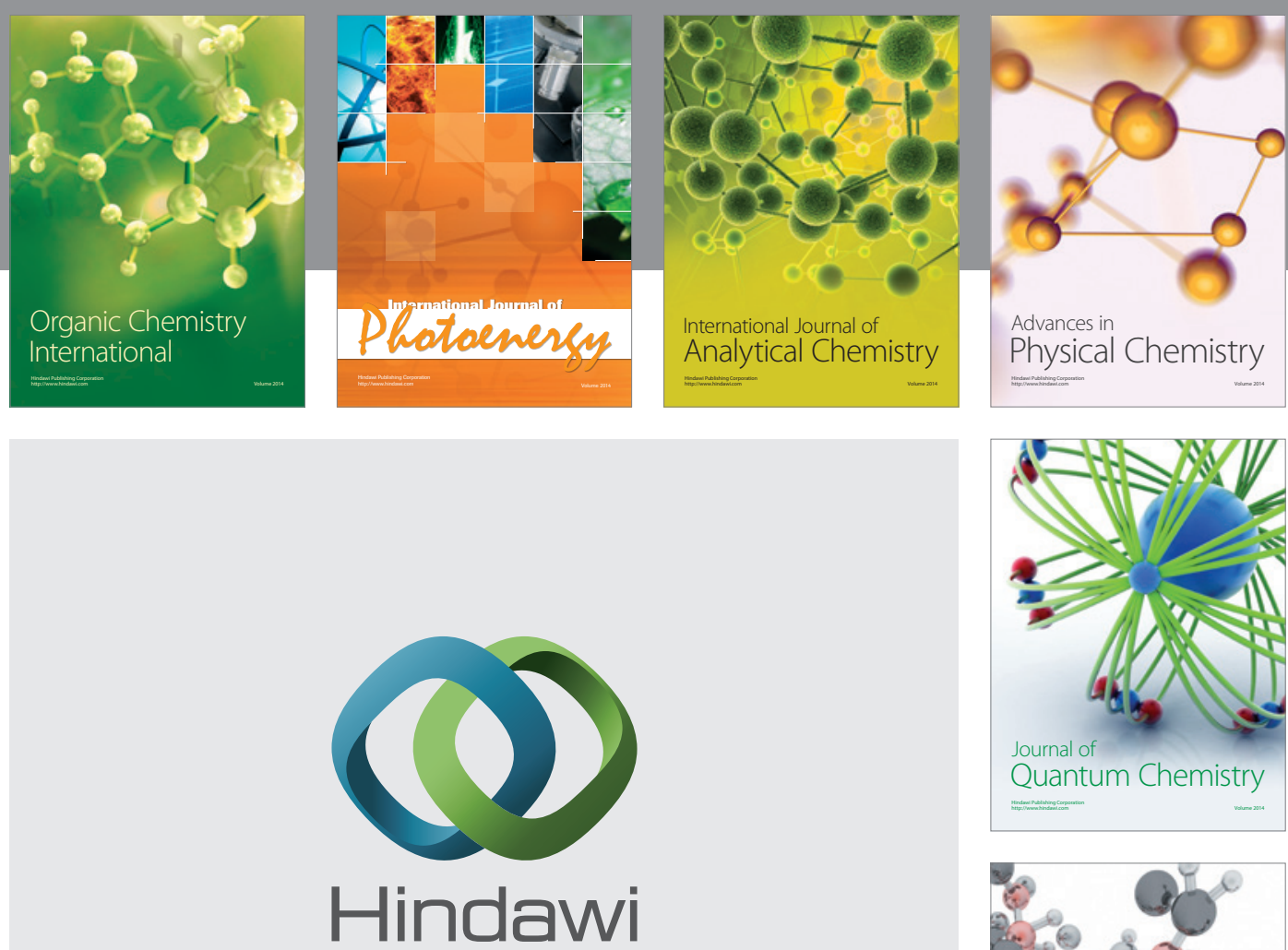

Submit your manuscripts at

https://www.hindawi.com

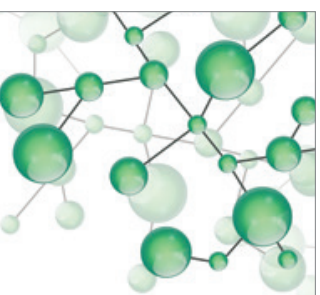

International Journal of

Inorganic Chemistry
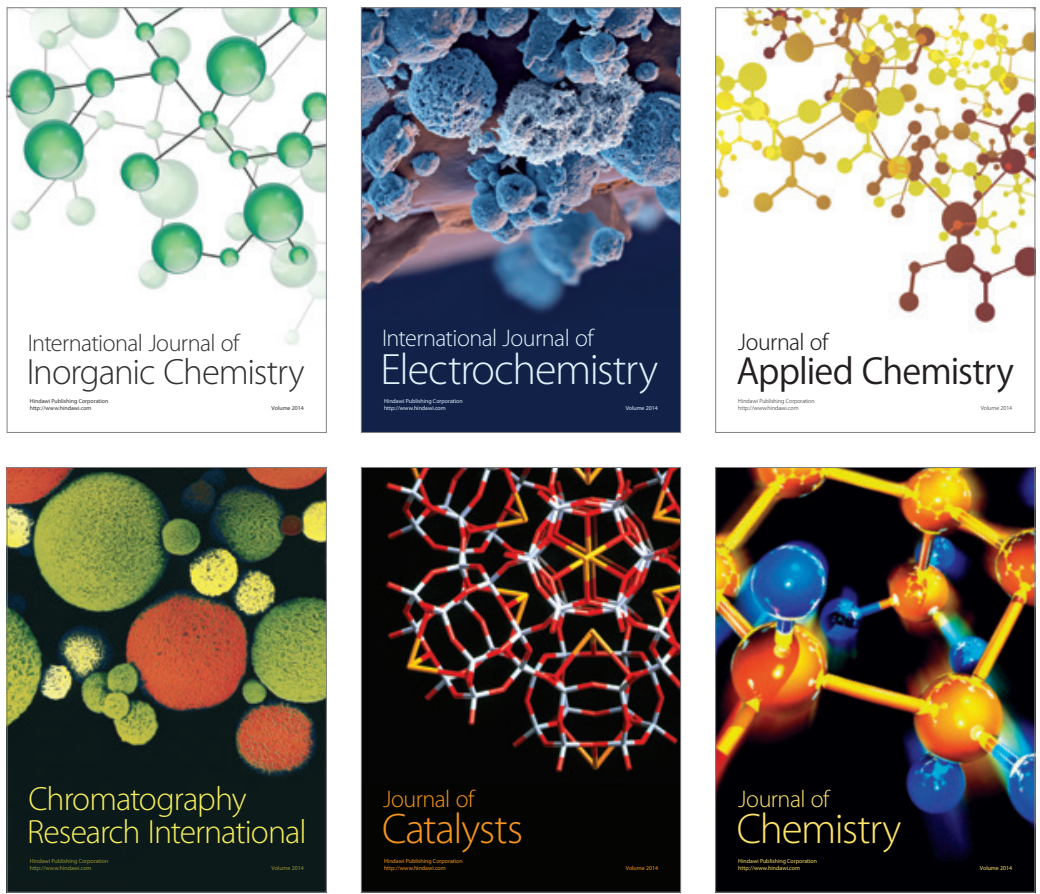

Journal of

Applied Chemistry
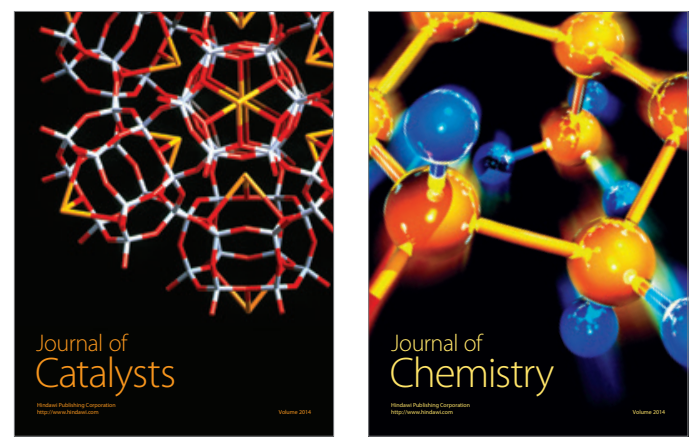
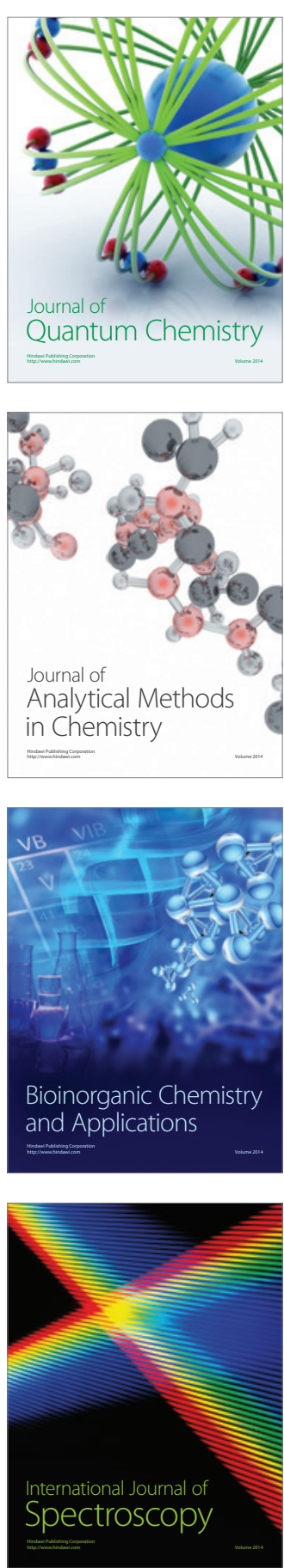